transmitted infections (STIs) doubled in older people between 1996 and 2003, the fastest rise in all age groups.

Aim(s)/objectives To assess the health care needs of women aged 40 and over attending an integrated sexual health clinic in South London.

Methods Retrospective case notes review of 200 randomly selected female patients aged 40 and over attending between 2nd June 2014 and 30th May 2015.

Results 1728 out of 5039 women (34\%) who attended the sexual health clinic were aged 40 and over. In the sample of 200, mean age was 46.6 years (range: $40-73$ years). Ethnicity: Black 111 (55\%), White 57 (29\%), Other 32 (16\%). 110 women (55\%) attended for STI-related reasons (symptoms/partner notification/possible exposure/treatment). 41\% attended for contraception and $10.5 \%$ for asymptomatic screen. Of 150 tested, 29 $(19.3 \%)$ had STIs. STIs were: genital herpes 8 (5.3\%), trichomoniasis $7(4.7 \%)$, genital warts $5(3.3 \%)$, chlamydia $2(1.3 \%)$ and gonorrhoea $1(0.7 \%)$. Overall condom use was $22.9 \%$.

Discussion/conclusion A significant proportion of women accessing sexual health services were aged 40 and over. 1 in 5 women were diagnosed with an STI. Under a quarter of women used condoms, indicating sexual risk taking behaviour. The sexual health needs of older people will continue to increase, given our rapidly ageing population. There is therefore a need to develop age-specific health promotion strategies and to challenge assumptions regarding sexuality in older age.

\section{P048 WHAT FACTORS CAUSE DELAY IN TERMINATION OF PREGNANCY? A LITERATURE REVIEW OF THE EVIDENCE}

Lotte Elton. London School of Hygiene and Tropical Medicine, London, UK

\subsection{6/sextrans-2016-052718.102}

Background/introduction Although abortions performed at earlier gestations are relatively medically safer and less costly, nonetheless in many settings there exists a small minority of women who receive abortions in the second trimester. The difficult circumstances faced by women seeking later abortions have been highlighted, but it is not always clear what factors lead to abortions being performed later in pregnancy.

Aim(s)/objectives To identify the causative factors of later (second trimester) abortion, analyse the impact of service provision on timing of abortion and highlight other factors relevant to delay in seeking or obtaining abortion.

Methods A literature search was conducted using Medline and Embase databases, and results were limited to English language studies from the last 20 years in settings where termination of pregnancy was legally available.

Results Most delays tended to act on one or more of three periods: identification of pregnancy, decision-making, and obtaining an abortion having made a decision. Delays in suspecting or confirming the pregnancy were key drivers in later termination and were particularly pronounced in young people; service-related delays were common, though small, and were often compounded by logistical factors such as financial difficulties.

Discussion/conclusion The causes of later abortion are many and complex, and very commonly overlap; more research is needed to analyse how these factors interact to cause delay. The association of low socioeconomic status with increased abortion delay suggests more must be done to ensure the accessibility of abortion services.

\begin{tabular}{ll} 
Abstract P049 Table 1 HIV+ MSM & \\
\hline ASPECT OF ASSESSMENT & Number (\%) $\mathbf{n}=\mathbf{8 5}$ \\
\hline Sexual history taken & $77(91)$ \\
If sexual history taken, Sexually active in past 12 months & $60(78)$ \\
Of those who are sexually active, STI screen offered & $58(97)$ \\
Of those with screen offered, STI screen done & $53(91)$ \\
STI detected: & $10(19)$ \\
1. Chlamydia trachomatis & $1(10)$ \\
2. Neisseria gonorrheae & $8(80)$ \\
3. Syphilis & $1(10)$ \\
4. Warts & $2(20)$ \\
5. Acute Hepatitis C & $2(20)$ \\
Recreational drug history & $63(74)$ \\
If recreational drug history taken, recreational drugs use disclosed & $17(27)$ \\
If recreational drug history taken, chemsex specifically disclosed & $3(5)$ \\
\hline
\end{tabular}

\section{P049 AUDIT: RATES OF SEXUAL HISTORY TAKING AND SCREENING IN HIV POSITIVE MEN WHO HAVE SEX WITH MEN (MSM)}

${ }^{1}$ Alasdair Macrae, ${ }^{2}$ Emily Lord, ${ }^{2}$ Annabel Forsythe, ${ }^{2}$ Jackie Sherrard*. ${ }^{1}$ Oxford University Medical School, Oxford, UK; ${ }^{2}$ Oxford University Hospitals NHS Foundation Trust, Oxford, UK

\subsection{6/sextrans-2016-052718.103}

Background/introduction Increased rates of STIs in MSM may in part be due to the emergence of 'chemsex'; use of recreational drugs in the context of high-risk sex. BASHH has set a target of $97 \%$ of MSM attending for a new episode being offered a screen (80\% acceptance). BASHH/BHIVA guidance recommends HIV-positive patients have 6 monthly sexual histories and annual STI screens.

Aim(s)/objectives To evaluate whether HIV positive MSM patients were asked about recreational drug use, including chemsex and assessed and screened for STIs during consultations.

Methods The notes of 142 HIV positive men seen in 2015 were available, of whom 85 were MSM. Information was collected regarding sexual history, recreational drug use documentation, STI screen offer and test results.

Results 77 (91\%) of the MSM had a sexual history documented, of whom $60(78 \%)$ were sexually active. STI screens were offered to 58/60 (97\%) of those who were sexually active and accepted by $53(91 \%) 10(19 \%)$ of these had an STI. A recreational drug history was taken in 63 (74\%) with 17 (27\%) admitting to use and $3(5 \%)$ to chemsex (Table 1).

Discussion/conclusion Sexual history documentation was below recommended levels. 19\% men tested had an STI highlighting that frequent screening in this group is essential. A quarter of patients admitted to recreational drug use, although how many were explicitly asked about chemsex is unclear. Given the increasing concern around this practice, questions about chemsex should be incorporated into the sexual history proforma.

\section{P050 IMPROVING MANAGEMENT AND PARTNER NOTIFICATION OUTCOMES OF WOMEN TREATED FOR PELVIC INFLAMMATORY DISEASE (PID) BY INNOVATIVE YET SIMPLE BESPOKE MEASURES}

Noel B Connolly*, Cheryl Stott, Mike Ward, Orla McQuillan. The Hathersage Centre for Contraception, Sexual Health \& HIV, Manchester Royal Infirmary, 280 Upper Brook Street, Manchester, M13 OFH, UK

10.1136/sextrans-2016-052718.104 